\title{
Gold/Chromium Metallizations for Electronic Devices
}

\section{MANUFACTURING TECHNOLOGY AND BEHAVIOUR}

\author{
Paul H. Holloway \\ University of Florida, Gainesville, FL., U.S.A.
}

\begin{abstract}
The thin films of gold which are applied so extensively in electronic devices are normally deposited over thin films of other metals in two, three or even four component metallization systems. The problems arising in such systems are vividly illustrated in this article on the gold/chromium metallization system developed in large measure at the Sandia Laboratories in Albuquerque, New Mexico.
\end{abstract}

Three main criteria are applied in the selection of metallization systems used in electronic devices. Firstly, these systems must have good conductivity to minimize power losses. Gold, with a resistivity of $2.4 \mu \Omega \mathrm{xcm}$, fulfils this condition and can tolerate high current densities. Secondly, metallizations must be inert or remain passive in operating environments if a high level of reliability is to be achieved. In this latter respect, gold is unequalled as an outer layer for metallizations because it does not form corrosion products in severe environments. Thirdly, metallization systems should be compatible with manufacturing processes. Anderson (1) and Mattox (2) have reviewed some of these processes and their operating parameters. Thin film systems can be categorized according to whether one, two, three or four components are used (Table $\mathrm{I}$ ) and, in general, it is desirable to use the least number of metals in order to simplify their preparation. Thus, the one-component system of aluminium has been used extensively and with great success in applications where corrosion resistance is not critical.
Apart from meeting the first two criteria listed above, gold is also compatible with beam-leaded and lead frame inter- and intraconnection technologies, it has substantial resistance to electromigration and can readily be deposited in thin layers by a variety of wet or vacuum processes. However, although Mattox (2) lisț gold as a one-component metallization, it is not frequently used as such because it does not adhere well to oxide (or oxidized) surfaces $(1,3)$. One or more metals are normally used at the gold-substrate interface to ensure strong bonding. Of the two-component systems listed in Table I, gold/chromium/s the most resistant to atmospheric corrosion (4 to 8 ) and its resistivity is generally lower than that of goldpalladium/chromium because of alloying effects between gold and palladium (7). The presence of palladium or platinum as $x$ in three-component systems of the gold/x/titanium type improves the corrosion resistance over that of gold/chromium (4), but also increases the metallization resistivity because of interdiffusion between gold and palladium or platinum $(9,10)$. Unalloyed palladium is not as inert

Table 1

Thin Film Metallization Systems Glassified According to the Number of Components Used. In part after (2)

\begin{tabular}{|c|c|c|c|}
\hline $\begin{array}{c}\text { One-component } \\
\text { systems }\end{array}$ & $\begin{array}{l}\text { Two component } \\
\text { systems* }\end{array}$ & $\begin{array}{l}\text { Three-component } \\
\text { systems }\end{array}$ & $\begin{array}{c}\text { Four }=\text { component } \\
\text { systems }\end{array}$ \\
\hline $\begin{array}{l}\mathrm{Al} \\
\mathrm{Cr}^{-} \\
\text {Nichrome }^{\oplus}(\mathrm{NiCr}) \\
\text { Mo } \\
\text { Au }\end{array}$ & $\begin{array}{c}\mathrm{Au} / \mathrm{Ti} \\
\mathrm{Au} / \mathrm{Nichrome} \\
\mathrm{Au} / \mathrm{Cr} \\
\mathrm{Au} / \mathrm{Mo} \\
\mathrm{Au} / \mathrm{Nb} \\
\mathrm{AuPd} / \mathrm{Cr}\end{array}$ & $\begin{array}{c}\mathrm{Au} / \mathrm{Pd} / \mathrm{TI} \\
\mathrm{Au} / \mathrm{Pt} / \mathrm{TI} \\
\mathrm{Pd} / \mathrm{Cu} / \mathrm{Nichrome}{ }^{\circ} \\
\mathrm{Pd} / \mathrm{Cu} / \mathrm{TI} \\
\mathrm{Au} / \mathrm{W} / \mathrm{TI} \\
\mathrm{Au} / \mathrm{Mo} / \mathrm{TI}\end{array}$ & $\begin{array}{l}\mathrm{Au} / \mathrm{Rh} / \mathrm{Pd} / \mathrm{Tl} \\
\mathrm{Au} / \mathrm{Ni} / \mathrm{Cu} / \mathrm{TI}\end{array}$ \\
\hline
\end{tabular}

*The sequence of the components is from the free surface towards the substrate, the sequence of deposition during manufacture is therefore the reverse of that indicated here. 


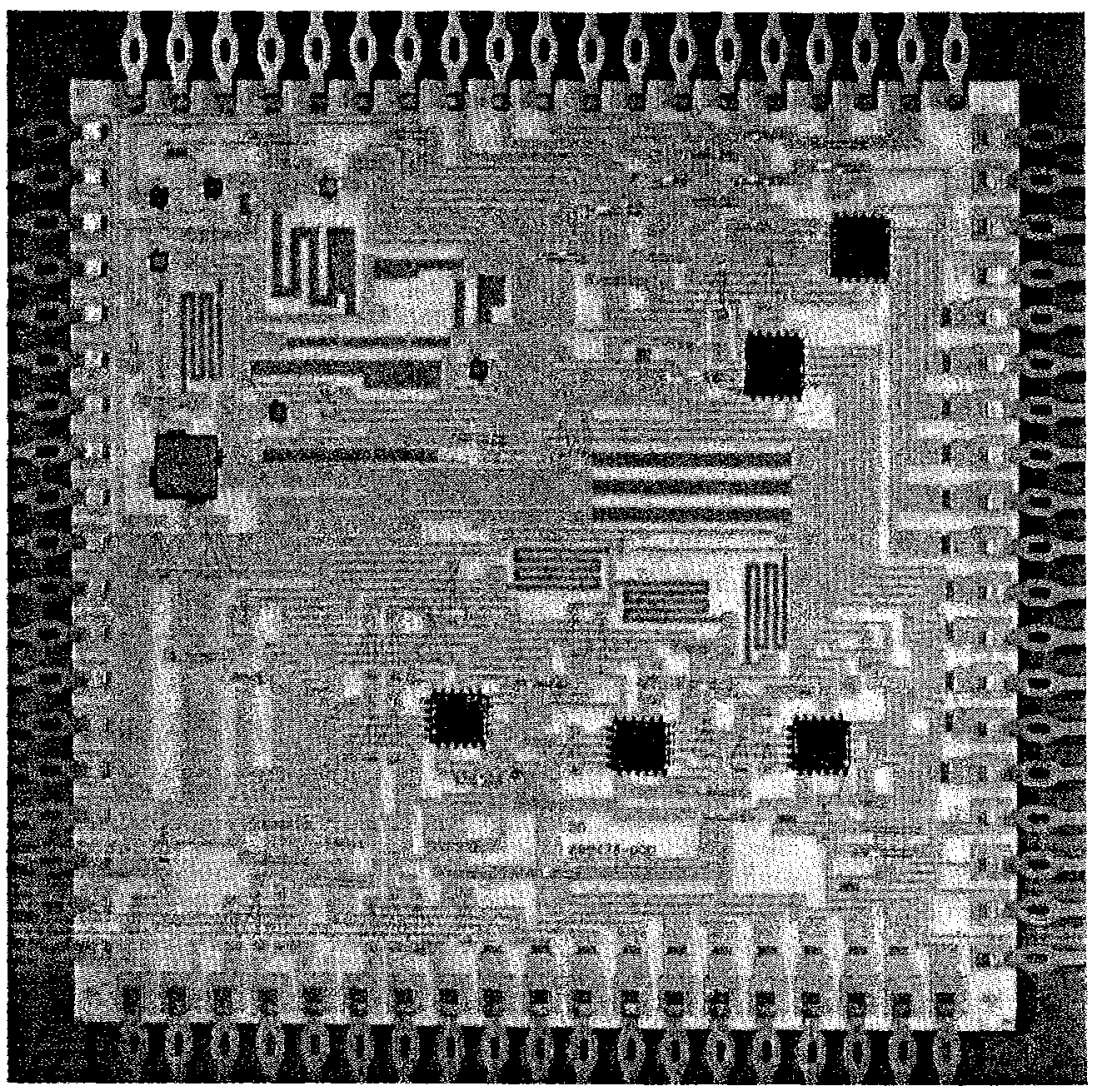

Fig. 1 This enlarged photograph of a typical hybrid microcircuit (HMC) made at Sandia Laboratories shows the white alumina substrate $(25 \times 25 \times 1.5$ $\mathrm{mm}$ ), the gold/chromium metallization and the greybrown tantalum nitride thin film resistors. Some of the metallized conductor segments are interconnected by thermocompression bonded thin gold wires. The active electronic functions of the circuit are performed by the square appliqué parts which appear as black or grey on this photograph. Electrical connection to the device after encapsulation is by means of the goldplated lead frame which is thermocompression bonded to the metallized pads at the edges of the assembly

as gold and is unsuitable as a substitute for it in highreliability devices.

While the gold/chromium system is relatively immune to corrosion in normal atmospheres, this is not the case when even trace amounts of halogens are present $(4,5,11,12)$. Furthermore, chromium is very mobile in the grain boundaries of gold. Both of these phenomena may cause problems during manufacture of devices. Although gold/chromium is used to metallize integrated circuits $(1,6,13)$ and capacitor terminations (14), the author's experience has been primarily with its use on hybrid microcircuits (HMC). This HMC technology, developed at Sandia Laboratories, will be used to illustrate typical manufacturing techniques and problems which may be encountered with the gold/chromium system.

\section{HMC Manufacturing Process}

A typical HMC, as shown in Figure 1, consists of an alumina substrate, $25 \times 25 \times 1.5 \mathrm{~mm}$ in size, upon which tantalum nitride is reactively sputtered to form thin film resistors. The conductors and bonding pads consist of a chromium adhesion layer some $30 \mathrm{~nm}$ thick, with a gold layer, some 3 to $6 \mu \mathrm{m}$ thick, sequentially deposited on top of the tantalum nitride. Intraconnections are made by thermocompression (TC) bonding (15) fine gold wires or gold beam-leaded devices. Interconnections are made with TC bonded gold-plated lead frames.
The HMC technology developed at the Sandia Laboratories consists of the following processing steps:

(1) Cleaning of the alumina substrates

(2) Sputtering of tantalum nitride thin film resistor material $(50 \mathrm{~nm})$

(3) Evaporation of chromium and gold film conductors $(30 \mathrm{~nm}$ chromium, 3000 to $6000 \mathrm{~nm}$ gold) in succession

(4) Resist application, conductor definition and etching

(5) Resist application, resistor definition and etching

(6) Resistor stabilization by heating in air for $\&$ hours at $300^{\circ} \mathrm{C}$

(7) Substrate sizing with a laser scribe and breaking

(8) Cleaning

(9) Bonding of lead frames

(10) Assembly of appliqué parts and beam-leaded devices, bonding of interconnecting wires

(11) Electrical testing

(12) Attaching of the lid using an epoxy adhesive.

This technology is further illustrated by the material-flow diagram of Figure 2. The conductor pattern is defined using a potassium iodide solution saturated with iodine $\left(\mathrm{KI}+\mathrm{I}_{2}\right)$ to etch gold and a ceric ammonium nitrate (CAN) solution to etch chromium (17). Additional details on these steps may be found in reviews $(16,17,18)$ or in actual process specifications (19). 


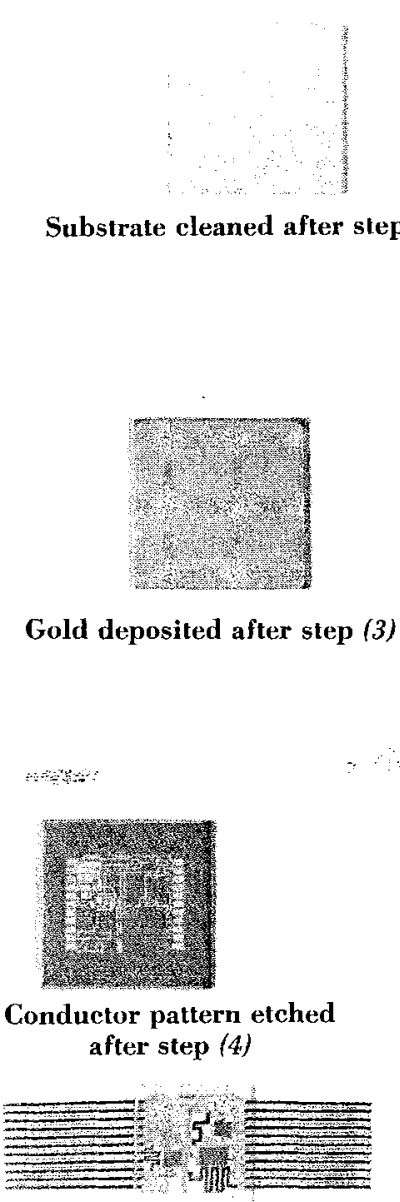

Substrate sized and lead frame attached after step (9)

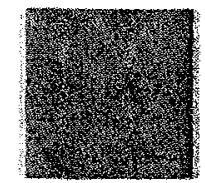

TaN deposited after step (2)

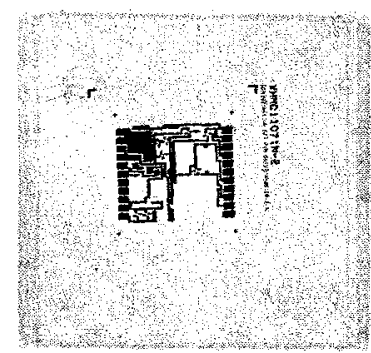

Conductor mask used in step (4)
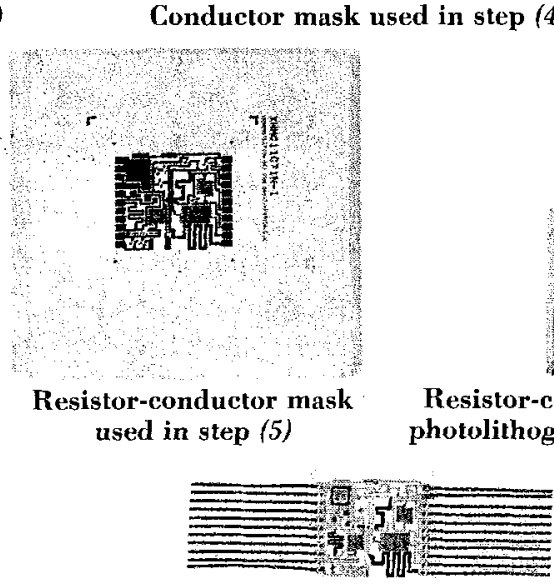

Beam-leaded devices, appliqué parts and interconnecting wires bonded after step (10)

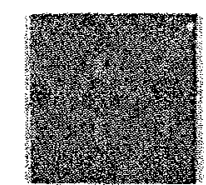

Chromium deposited in step (3)

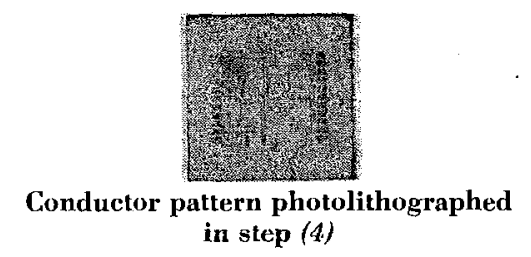

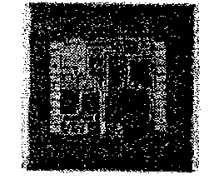

Resistor-conductor pattern photolithographed in step (5)

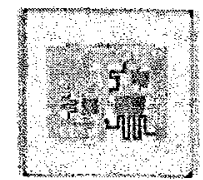

Resistor-conductor pattern etched after step (5)

Fig. 2 Illustration of some of the processing steps in the manufacturing technology of HMC's with gold/chromium metallization which was developed at Sandia Laboratories in Albuquerque, NM., U.S.A. Additional details on the process are given in the text of this article

Deposition of the gold/chromium metallization is carried out on carefully stored, oxidized tantalum nitride surfaces without breaking vacuum and at pressures (prior to evaporation) below $3 \times 10^{-4} \mathrm{~Pa}$. Data by Speight et al. (4) suggest that the contact resistance of these metallizations may be sensitive to the background pressure during deposition.

Substrate temperatures ranging from 200 to $350^{\circ} \mathrm{C}$ have been used with good results for the deposition of gold/chromium. Data by Clay et al. (20) show that the chromium resistance decreased with increases in substrate temperature while the reverse was observed for the gold. These effects result from recovery of the chromium film and from enhanced diffusion of chromium into the gold film with increasing temperature respectively. The grain size of the gold increased with the substrate temperature, probably because the resulting higher atomic mobility favours growth but not nucleation. The optimum substrate temperature seemed to be about $300^{\circ} \mathrm{C}(20)$.

Since chromium is only used as an adhesion layer, its thickness can be minimal. Weaver and Hill (21) found that $40 \mathrm{~nm}$ of chromium was required for good adhesion of gold to alumina, while Haq et al. (3) reported good adhesion for only $1 \mathrm{~nm}$ of chromium and studies at Sandia Laboratories (11) indicated good adhesion for $10 \mathrm{~nm}$. In practice the chromium film thickness is therefore specified to be $30 \pm 10 \mathrm{~nm}$ to allow for process variation. Clay et al. (20) report that the optimum deposition rate is from 0.1 to $0.3 \mathrm{~nm} / \mathrm{s}$. If extremely high deposition rates or very thick films (more than $100 \mathrm{~nm}$ ) are used, the films may contain stresses of such magnitude as to cause delamination (2).

Gold thicknesses of $3 \mu \mathrm{m}$ are normally used for typical HMC's although $6 \mu \mathrm{m}$ films are used for radio frequency appliçations. The gold film must be sufficiently thick to minimize chromium diffusion to the free surface (see below) and to minimize the number of pinholes through which corrosion could occur $(12,22)$. Optimum deposition rates are about 2 to 3 $\mathrm{nm} / \mathrm{s}(20)$ although rates up to $10 \mathrm{~nm} / \mathrm{s}$ have been successfully used. As for chromium, internal stresses can be excessive in thick gold or in films deposited at high rates (2): The deposited films have a rough nodular 


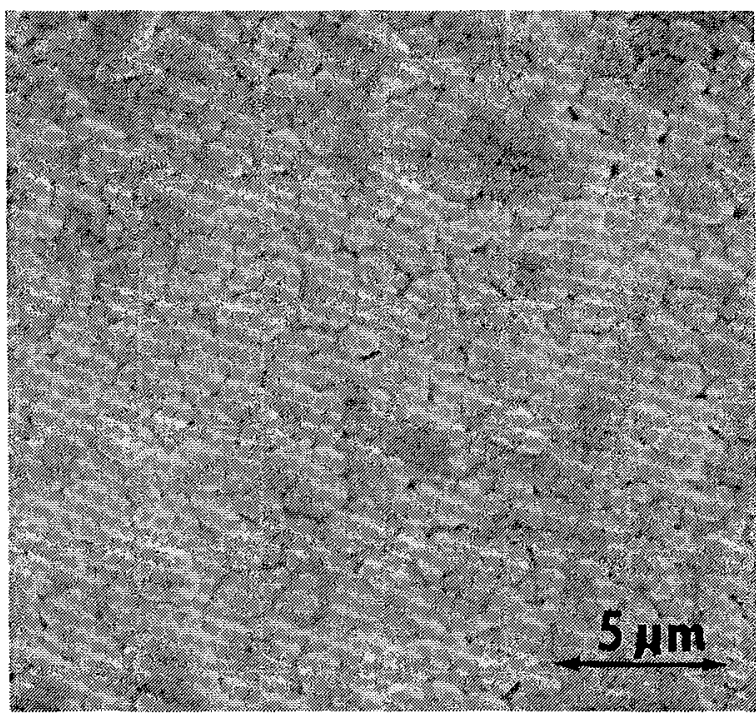

Fig. 3 Scanning electron micrograph of a thin film of gold deposited onto an alumina substrate. The nodular topography of the gold is related to that of the substrate but does not reproduce it in every detail. Also, individual gold nodules are not necessarily single grains

appearance (Figure 3) which is similar to that of the alumina substrate. It is often assumed that the nodules replicate the substrate and that they correspond to individual gold grains - neither is true. While the substrate topography certainly influences the gold nodule size, other factors such as substrate temperature, deposition rate and chromium thickness also affect the topography of the gold (23).

By thinning gold films and examining them with transmission electron microscopy, Holloway and Nelson have shown that each gold nodule can consist of several grains (23). Thus, the microstructure of the gold film is related to processing variables by mechanisms which are still poorly understood.

\section{Chromium Diffusion Effects}

While the manufacturing procedure detailed above proved generally satisfactory, the metallization resistivity increased (see Table II) during the stabilization step (6) and problems were encountered at steps (9) and (10) during TC bonding of lead frames and fine wires $(17,20,24,25,26)$. The origin of the bonding problems was also traced to step (6), in which substrates with resistors and conductors defined are heated in air at $300^{\circ} \mathrm{C}$ for 2 hours to oxidize the tantalum nitride films. This treatment stabilizes their resistance against change during their 20-year expected lifetime. Data in Table II show that before stabilization, the average $90^{\circ}$ peel strength $(25,27)$ of bonded lead frames was $8.4 \mathrm{~N}$ and all failures were located at the heel (that is, at the edge of the bonding tool deformation area). After resistor stabilization, the average peel strength was $5.8 \mathrm{~N}$ and most failures were delaminations (that is, separation at the original bonding interface). Auger electron spectra shown in Figure 4 clearly demonstrated that the resistor stabilization treatment led to the formation of $\mathrm{Cr}_{2} \mathrm{O}_{3}$ on the gold surface. The oxide layer was determined to be approximately $0.8 \mathrm{~nm}$ thick by a signal intensity analysis (28). To verify that such a thin film could degrade TC bondability, thin layers of $\mathrm{Cr}_{2} \mathrm{O}_{3}$ were vapour-deposited onto gold and their effect upon lead frame peel strength was measured. The results (Table II) show less effect for 0.6 but more for $1.5 \mathrm{~nm}$ of vapour-deposited $\mathrm{Cr}_{2} \mathrm{O}_{3}$ as compared to the resistor stabilization treatment. It can therefore be concluded that films of $\mathrm{Cr}_{2} \mathrm{O}_{3}, 1 \mathrm{~nm}$ or less in thickness, can seriously degrade the TC bondability of gold.

In step (6) of the manufacturing process, $\mathrm{Cr}_{2} \mathrm{O}_{3}$ must form on the free surface of the metallization by diffusion of chromium through gold. Such diffusion has been studied by resistivity $(29,30)$, work function

Table II

Effect of Hybrid Microcircuit Resistor Stabilization Treatment (2 Hours at $300^{\circ} \mathrm{C}$ in Air) and of Contamination by $\mathrm{Cr}_{2} \mathrm{O}_{3}$ on the Bondability of Gold/Chromium Metallizations and the Resistivity of Gold Conductors

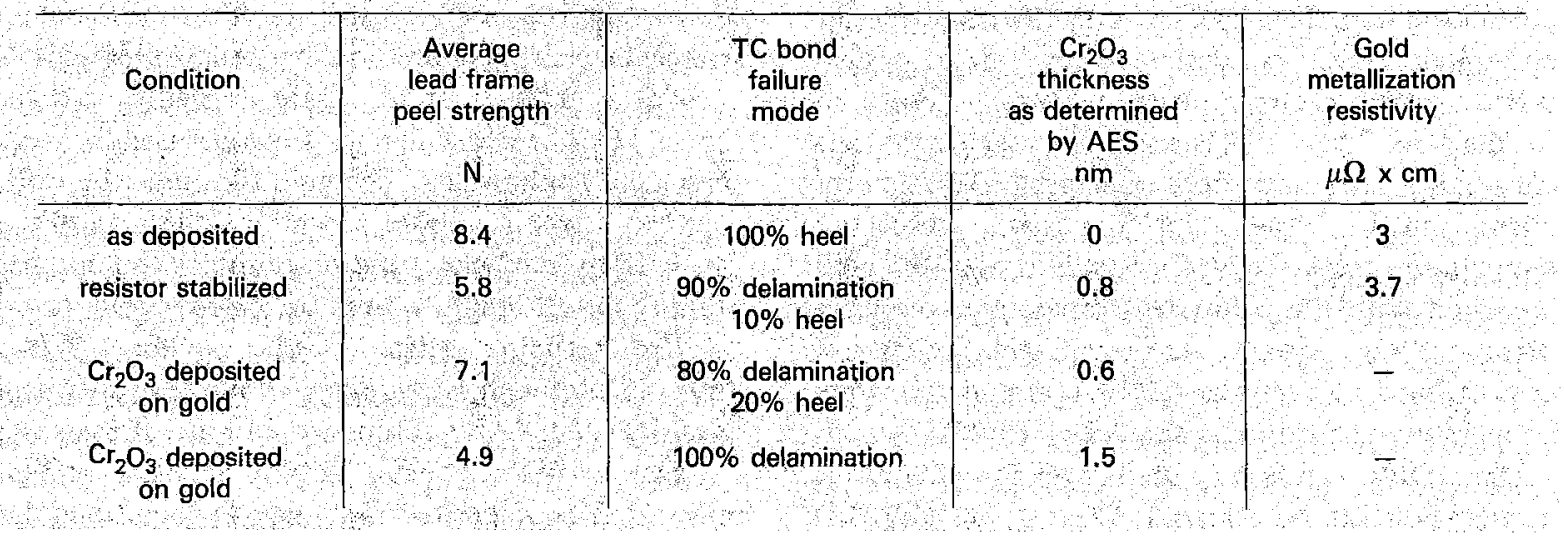


Fig. 4 Auger electron spectra from the surface of a gold/chromium metallization (a) as deposited and (b) after stabilization of the tantalum nitride resistors by heating at $300^{\circ} \mathrm{C}$ for 2 hours in air. During the heat trentment, quite significant amounts of chromium have migrated by grain boundary diffusion from the metallization-substrate interface to the surface of the gold

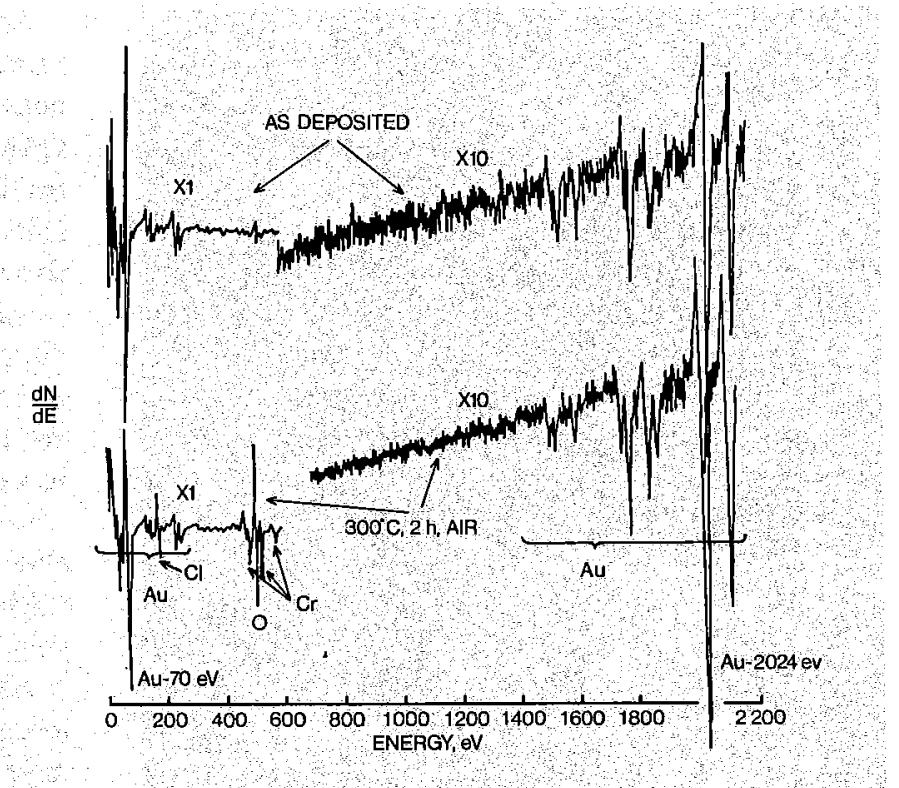

(31), Rutherford backscattering (32), electron microscopy (33), electron probe microanalysis (34) and in particular detail using Auger electron spectroscopy (AES) and ion scattering spectroscopy $(35,36)$. The resulting data clearly establish that grain boundary diffusion is the dominant transport mechanism by which chromium migrates to the surface of the gold where it forms $\mathrm{Cr}_{2} \mathrm{O}_{3}(23,35,36)$. Grain boundary diffusion also explains why metallization resistivity increases so dramatically during resistor stabilization. Chromium rapidly moves throughout the thickness of the gold films via grain boundaries from where some of it also diffuses into the bulk of the gold grains. This bulk contamination of gold by chromium results in resistivity increases of 25 per cent in only 2 hours at $300^{\circ} \mathrm{C}$.

Another effect of grain boundary diffusion was first noticed by Kendrick (33) and then studied in detail by Hampy et al. (37). As a result of diffusion, chromium is preferentially removed from the adhesion layer where gold grain boundaries emerge. Any counter-flux of gold is insufficient to compensate for the chromium flux, thus a labyrinth of voids is created as shown in Figure 5. Since this labyrinth of

Fig. 5 Scanning electron micrograph of a thin film of chromium on glass after a simulated resistor stabilization heat treatment $\left(2\right.$ hours at $300^{\circ} \mathrm{C}$ in air) and subsequent removal of the gold layer that had initially been deposited above it. During heat treatment, grain boundary diffusion of chromium through gold took place which resulted in preferential removal of the former metal where gold grain boundaries emerged against the chromium adhesion layer at the metallization-glass interface. Thus, the pattern of chromium islands separated by a labyrinth of voids, which is arrowed here, resulted. After (37) voids is connected to the environment at the edge of conductors, corrosion of the remaining chromium 'islands' may be greatly enhanced as discussed below.

To produce reliable $\mathrm{HMC}$ 's, $\mathrm{Cr}_{2} \mathrm{O}_{3}$ formation must be prevented or, if the oxide forms, it must be chemically removed from the gold surface prior to TC bonding. Holloway and Nelson (38) have shown that subsequent chromium diffusion is considerably slowed if gold deposition is interrupted and the deposition chamber is filled with oxygen to pressures of around $10^{-3} \mathrm{~Pa}$ during step (3) of the manufacturing process. With the introduction of such a treatment, the lead frame peel strengths and failure modes were the same before and after resistor stabilization. Furthermore, the gold resistivity was approximately 2.6 rather than around $3.6 \mu \Omega \times \mathrm{cm}$ after the standard deposition procedure.

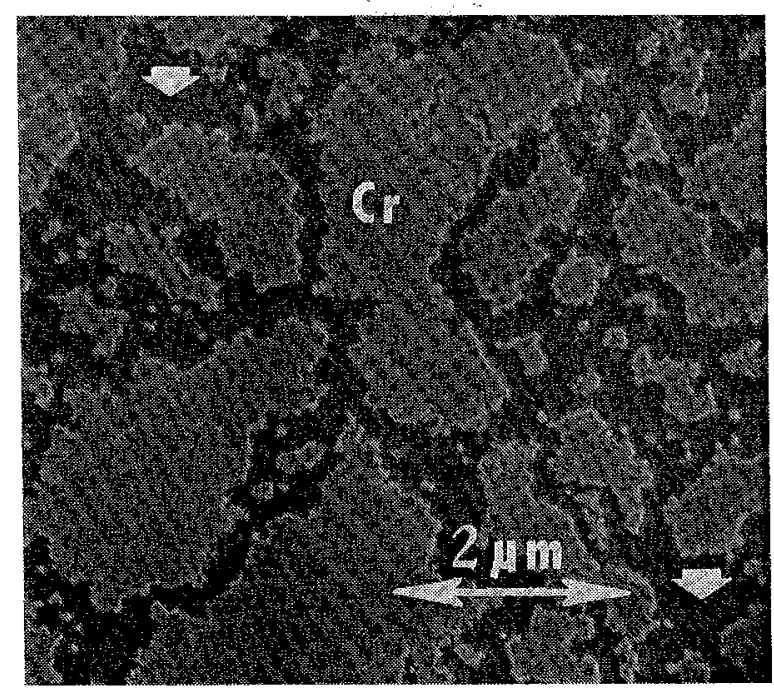




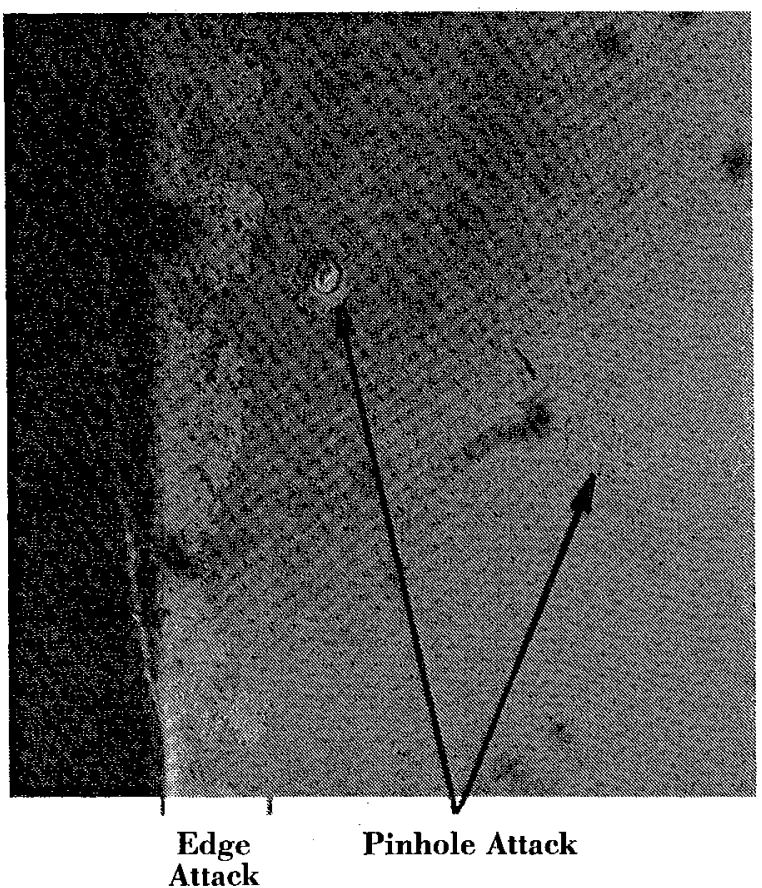

Fig. 6 Evidence of undercutting and pinhole attack of a gold/chromium metallization on glass by ceric ammonium nitrate (CAN). Prior to the attack, this sample was submitted to a simulated resistor stabilization treatment of 2 hours at $300^{\circ} \mathrm{C}$ in air. Data by Palmer and Wright (12) suggest that the extent of attack is lesser after stabilization than immediately after deposition but there are indications that this difference may be temporary only
O6 WEEKS STORAGE BETWEEN STABILIZATION AND LEACHING -NO STORAGE BETWEEN STABILIZATION AND LEACHING

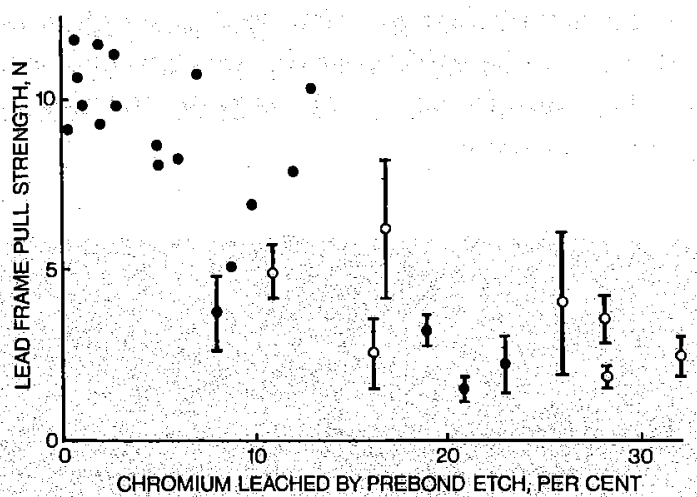

Fig. 7 Lead frame pull strength vs, percentage of total chromium removed by exposure of gold $/ 30 \mathrm{~mm}$ chromium-metallized HMC's to ceric ammonium nitrate (CAN) for $10 \mathrm{~min}$, at room temperature for pre-bond etching. All samples were submitted to a tantalum nitride resistor stabilization treatment prior to being tested. Far less chromium leaching, and concommitant ligher pull strengths, are observed in samples etched immediately after the stabilization treatment than in samples stored for 6 weeks in the manufacturing environment between the two operations. After (12)
Chemical cleaning procedures also proved effective in restoring the bondability of gold surfaces contaminated with $\mathrm{Cr}_{2} \mathrm{O}_{3}(24,25)$. Both $\mathrm{KI}+\mathrm{I}_{2}$ and CAN may be used to improve bonding, but their mechanisms of action are different. On the one hand, $\mathrm{KI}+\mathrm{I}_{2}$ preferentially attacks the gold at nodule boundaries and restores bondability because the roughened surface allows more deformation during bonding. However, if the contamination layer is continuous and thick, $\mathrm{KI}+\mathrm{I}_{2}$ may not be able to remove sufficient gold and restore bondability (25). On the other hand, CAN actually removes the $\mathrm{Cr}_{2} \mathrm{O}_{3}$ and even removes low concentrations of hydrocarbons that may also be present at the gold surface. Therefore with CAN, bondability is restored by re-establishing goldgold contact.

When CAN is used for pre-bond chemical cleaning, there is an obvious danger of undercutting or attacking the chromium adhesion layer through pinholes (Figure 6). Data by Holloway and Long $(24,25)$ and Palmer and Wright (12) show that extensive reaction does not normally occur during pre-bond cleaning. However in some instances, CAN exposure may remove over 10 per cent of the chromium present in the adhesion layer (as measured by atomic dsorption analysis of the etchant) and result in poor lead frame peel strengths (Figure 7). Thus, under certain undefined conditions, gold/chromium films are susceptible to excessive attack when CAN is used to remove $\mathrm{Cr}_{2} \mathrm{O}_{3}$ before TC bonding. Data by Mattox and Sowell (39) suggest that this attack may be related to the porosity of the gold film which is controlled in part by the alumina porosity.

Diffusion in the gold-chromium system has been a problem in integrated circuits also. Magni et al. (13) have shown that gold diffuses rapidly through chromium and alloys with underlying silicon. This causes anomalous behaviour and excessive noise in electronic devices.

\section{Corrosion}

A film adhesion problem has sometimes been observed after storage of gold/chromium metallized devices in the manufacturing environment. This problem was characterized by very low strength failure of TC bonded leads and by 'peel-back' of gold films. AES data showed that the chromium layer was no longer present and traces of cerium and halogens were found on the delaminated gold and on the tantalum nitride surface. As pointed out earlier, halogens dramatically accelerate the corrosion of gold/ chromium metallizations. Hampy et al. (11) have shown that iodine vapours cause severe degradation even in times as short as 1 hour at room temperature. Iodine vapours and moisture are always present in the photolithographic environment that is an integral 
part of electronic device processing. Data in Figure 7 show that the strength of TC bonds decreased when these were performed on devices that had been stored between resistor stabilization and pre-bond etching. The facts that only samples stored for appreciable times exhibited failure and that failure rates peaked in spring and summer when humidity was high point to a significant part played by environmental conditions. Not unexpectedly, the chromium-depleted labyrinth observed by Hampy et al. (37) increases the danger of corrosion. The small interconnecting network of voids allows liquid formation at lower relative humidities and reduces the areas over which corrosion must occur in order to cause loss of adhesion. Thus, chromium diffusion affects both bondability and resistance to corrosion.

These data show that controlled storage conditions are necessary for gold/chromium metallization. Indêed, no corrosion has been observed for HMC's stored in halogen-free environments or in hermetically sealed packages.

\section{Other Intra- and Interconnections}

TC bonding of gold to gold is affected by contamination irrespective of the metallization system. With regard to such problems, gold/chromium metallizations do not exhibit unusual behaviour when compared with other systems. For instance, besides that by $\mathrm{Cr}_{2} \mathrm{O}_{3}$, bond strength degradation by photoresist residues only $1.0 \mathrm{~nm}$ thick has also been demonstrated (40). Holloway and Bushmire have shown that ozone and ultra-violet radiation plus ozone remove photoresist residues from contaminated surfaces and restore their bondability. These authors have also studied the susceptibility of different bonding techniques to contamination and found wire bonding to be most sensitive, while ultrasonic techniques were least sensitive (41). Jellison has studied the effect of heating on the bondability of photoresistcontaminated substrates. His results show that the bond strength increases with heat treatment time after bonding, apparently as the consequence of plastic deformation recovery (42).

Yost et al. $(43,44)$ have studied the lead-indium system for solder attachment as an alternative to the traditional lead-tin systems. Lead-indium alloys dissolve gold to a lesser extent and show good thermal fatigue lifetimes. Very few fatigue cracks and good bond strength were observed after 500 cycles between -55 and $+125^{\circ} \mathrm{C}(45)$.

Palmer et al. (46) have studied techniques to avoid the formation of brittle intermetallic phases when a gold metallization is bonded to aluminium-metallized parts (the so-called 'purple plague' problem (47)). These authors have found that a small disk of Kovar (25 nickel/17 cobalt/0.2 manganese/bal. iron, per cent) plated with gold on one side and aluminium on the other can alleviate this problem. The Kovar serves as an effective diffusion barrier preventing the formation of brittle phases and/or Kirkendall voids.

\section{Conclusion}

Reliable thin film conductors can be produced on microelectronic devices using the gold/chromium system. The processing technology for this system is well defined and easily accomplished. However, grain boundary diffusion of chromium and halogenenhanced corrosion may constitute two major limitations for this metallization. Problems arising from both may be diminished or even avoided by proper processing and by storage and operation in appropriate environments. Thus, the system is compatible with the manufacture of high-reliability microelectronics.

\section{Acknowledgements}

Much of the work reported here was performed at Sandia Laboratories and was supported by the U.S. Department of Energy.

\section{References}

1 J. C. Anderson, Thin Solid Films, 1972, 12, 1-15

2 D. M. Mattox, Thin Solid Films, 1973, 18, 173-186

3 K. E. Haq; K. H. Behrndt and I. Kobin, f. Vac. Sci. Technol., $1969,6,148-152$

4 J. D. Speight, D. Gerstenberg and H. Basseches in 'Proc. 9th Annu. Int. Reliab. Phys. Symp.', Las Vegas, 1971, pp. 195-203

5 A. T. English and P. A. Turner, f. Electron. Mater., 1972, 1, $1-9$

6 L. E. Terry and R. W. Wilson, Proc. IEEE, 1969, 57, 1580-1586

7 R. W. Berry, P. M. Hall and M. T. Harris, 'Thin Film Technology', Van Nostrand-Reinhold, New York, 1968, p. 337

8 J. J. Barb, IEEE Trans. Electron Devices, 1969, ED16, 351-356

9 J. M. Poate, P. A. Turner and W. J. De Bonte, F. Appl. Phys., $1975,46,4275-4283$

10 P. M. Hall, J. M. Morabito and J. M. Poate, Thin Solid Films, 1976, 33, 107-134

11 R. E. Hampy, J. Villaneuva and F. P. Ganyard, Sandia Laboratories'Rep. SAND 78-0646, July 1978*

12 D. W. Palmer and R. E. Wright, Sandia Laboratories Rep SAND 76-0414, Sept. 1976*

13 G. Majni, G. Ottavani and M. Prudenziati, Thin Solid Films, $1976,38,15-19$

14 M. Tierman, U.S. Patent 3,638,035 (1972); see Chem. Abstr., 1976,118938

15 R. F. Tylecote, 'The Solid Phase Welding of Metals', St. Martin's Press, New York, 1968; Gold Bull., 1978, 11, (3), 74-80

16 C. $M$. Tapp and T. A. Wiley, Sandia Laboratories Rep. SLA-73-1063, June 1973*

17 R. L. Long, Jr., Sandia Laboratories Rep. SC-DR-72-0887, Dec. $1972^{\star}$

18 C. M. Tapp and R. K. Traeger, Sandia Laboratories Rep. SLA-74-0009, June 1974*

19 C. M. Tapp and D. J. Sharp, Sandia Laboratories Rep. SLA-74-0300, June 1974*

20 F. A. Clay, N. T. Panousis and R. W. Pierce in 'Proc. 24th Electron, Components Conf.', Washington, D.C., 1974, pp. 98-104; IEEE Trans. Parts Hybrids Packag., 1974, PHP10, 258-262

21 C. Weaver and R. M. Hill, Philos. Mag., 1959, 4, 1107-1111

22 D. F. Weirauch, Ceram. Bull., 1974, 53, 260

23 P. H. Holloway and G. C. Nelson, Sandia Laboratories Rep. SAND 75-0216, May 1975*

24 P. H. Holloway and R. L. Long, Jr., Sandia Laboratories Rep. SLA-73-1049, March 1974* 
25 P. H. Holloway and R. L. Long, Jr., IEEE Trans. Parts Hybrids Packag., 1975, PHP11, 83-88

26 N. T. Panousis and H. B. Bonham in 'Proc. 11th Annu. Reliab. Phys. Conf.', Las Vegas, 1973, pp.; 21-25

27 D. R. Johnson, Sandia Laboratories Rep. SC-DR-71-0539 Dec. $1971^{\star}$

28 P. H. Holloway, 7. Vac. Sci. Technol., 1975, 12, 1418-1422

29 I. R. Rairden, C. A. Neugebauer and R. A. Sigsbee, Metall. Trans., 1971, 2A, 719-22

30 G. L. Schnable and R. S. Keen, Tech. Rep. No. RADC TR-66-165, 1966*

31 R. E. Thomas and G. A. Haas, f. Appl. Phys., 1972, 43, 4900-4907

32 J. K. Hirvonen, W. H. Weisenberger, J. E. Westmoreland and R. A. Meussner, Appl. Phys. Lett., 1972, 21, 37-39

33 P. S. Kendrick, Nature, 1968, 217, 1249-1250

34 A. L. Pranatis, 'Diffusion Studies for Microcircuit Metallizations', Report of NRL. Progress, Naval Research Laboratory, Washington, D.C., May 1971, p. 21

35 G. C. Nelson and P. H. Holloway in 'Surface Analysis Techniques for Metallurgical Applications', ASTM STP 596, American Society for Testing and Materials, Philadelphia PA., 1976 , pp. 68.78

36 P. H. Holloway, D. E. Amos and G. C. Nelson, F. Appl. Phys., $1976,47,3769-3775$
37 R. E. Hampy, F. G. Yost and F. P. Ganyard, 7. Vac. Sci. Technol. $1979, \mathbf{1 6}, 25-30$

38 P. H. Holloway and G. C. Nelson, Thin Solid Films, 1976, 35, L13-L16

39 D. M. Mattox and R. R. Sowell in 'Proc. 7th Int. Vac. Congr \& 3rd Int. Conf. Solid Surf.', Vienna, 1977, pp. 2659-2662

40 P. H. Holloway and D. W. Bushmire in 'Proc. 12th Int. Symp. Reliab. Phys.', Las Vegas, 1974, pp. 180-186

41 D. W. Bushmire and P. H. Holloway, in 'Proc. Int. Microelectron. Symp.', Vancouver, B.C., Int. Soc. for Hybrid Microelectron., P.O. Box 3255, Montgomery, AL. 36109 , U.S.A., 1975, pp. $402-408$

$42 \mathrm{~J}$. L. Jellison in 'Proc. 25th Electron. Components Conf.', Washington, D.C., 1975, p. 271-277

43 F. G. Yost, Gold Bull., 1977, 10, (4), 94-100

44 F. G. Yost, F. Electron. Mater., 1974, 3, 353-369

45 H. C. Olson and G. L. Knauss, Sandia Laboratories Rep. SLA-73-1084, Oct. 1974^

46 D. W. Palmer and F. P. Ganyard, IEEE Trans. Components Hybrids Manuf. Technol, 1978, CHMT1, 219-222

47 E. Philofsky, Solid State Electron., 1970, 13, 1391-1399

*Available from National Technical Information Service, U.S. Department of Commerce, 5825 Port Royal Road, P.O. Box 1153 Springfield, VA. 22151, U.S.A

\section{Automatic Selective Brush Plating of Gold}

\section{APPLICATION TO TRANSISTOR AND INTEGRATED CIRCUIT HEADERS}

The selective gold plating of intricately shaped articles presents difficulties and for many years transistor headers were barrel-plated despite the fact that gold was needed only on those areas where wire or wafer bonding was required. The restriction of gold plating essentially to these areas is made possible, however, using equipment which has been developed by the Auric Corporation of Newark, NJ., (U.S.Patents 3,951,772 and 4,048,043).

In this, the headers are carried on a stainless steel band with the surface to be plated at a fixed height above a moving felt belt which is kept impregnated with electrolyte from the gold plating bath through which it passes. A copper brush serves as the cathode and platinum mesh as the anode. A proprietary electrolyte (Auric 609), which is a neutral gold bath containing citrates and phosphates, or its equivalent, is recommended for use with the equipment, which can be adapted to plate most types of headers. These are fed into the machine after cleaning by normal procedures and drying, and after plating are unloaded automatically into a container of distilled water. They are then rinsed and dried.

Depending on the design of the units and the gold thickness desired, the equipment will plate 8000 to 14000 headers per hour at an energy consumption which is a fraction of that in barrel-plating. The resulting gold coatings have been found to give higher bonding yields than those produced by barrel-plating, and the equipment is approved for use by six major semiconductor manufacturers.

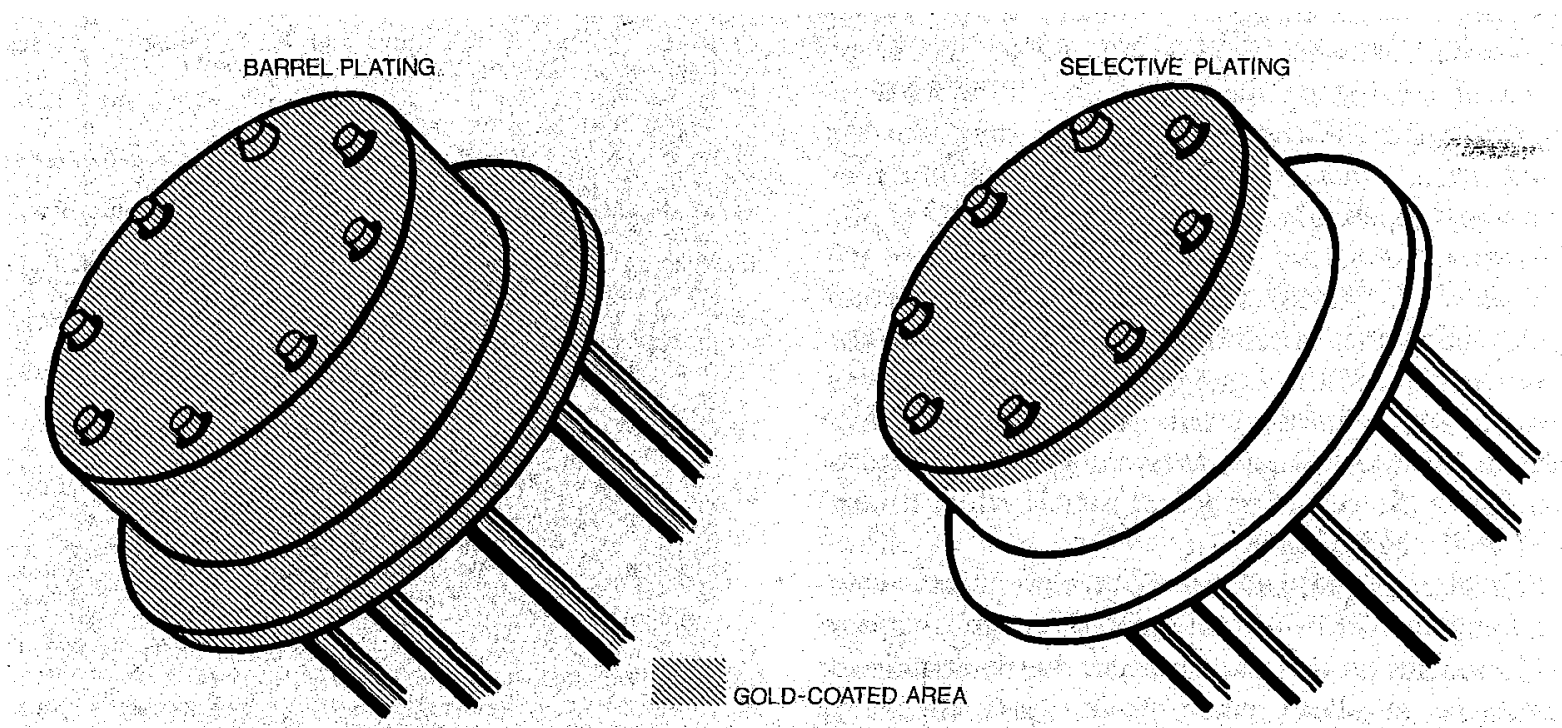

Schematic representation of the results of barrel-plating and selective brush plating transistor headers with gold 